\title{
El sudeste asiático a examen: lecciones y aprendizajes del proceso de integración
}

\author{
The Asian southeast examination: Lessons and learnings of the \\ integration process \\ Yair Candelario Hernández Peña ${ }^{1}$ y Marcela Reyes Ruiz ${ }^{2}$
}

\begin{abstract}
Resumen
El propósito del artículo es, analizar el cómo ha sido la integración en la subregión del sudeste asiático a través de un "examen" a los procesos de integración que se han gestado en la subregión, entre ellos la Asociación de Naciones del Sudeste Asiático (ASEAN y El Foro Económico de Asia Pacífico (APEC). La importancia por indagar el proceso de integración, radica en que el regionalismo expresado en integración, se origina en 1967, ello con la conformación de la ASEAN, posicionando a la subregión dentro del mapa de los regionalismos y dentro de los primeros a nivel mundial. Algunos resultados son, la construcción de una integración con base en el regionalismo abierto, fuertes lazos económicos entre los países de la región, sigue siendo una zona inestable, entre otros.
\end{abstract}

Palabras clave: Sudeste Asiático, ASEAN, Proceso de Integración, APEC, Evaluación

\section{Summary}

The purpose of the article is to analyze how integration has been in the subregion of Southeast Asia through an "examination" of the integration processes that have taken place in the sub region, including the Association of Southeast Asian Nations (ASEAN), and Asia-Pacific Economic Cooperation (APEC). The importance of investigating the integration process lies in the fact that regionalism expressed in integration originates in 1967, with the formation of ASEAN, positioning the subregion within the map of the region regionalism and among the first worldwide, some results are, the construction of an integration based on open regionalism, strong economic ties between

\footnotetext{
1 Estudiante del Doctorado en Relaciones Transpacíficas en UCOL Docente de Asignatura en UABC. yhernandez21@ucol.mx

2 Doctora en Estudios del Desarrollo Global por UABC. Profesora Investigadora en UABC marcelareyes@uabc.edu.mx
}

Vol. 8 Núm. 14 Enero - Junio 2018 


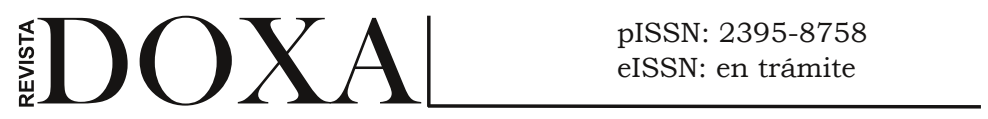

the countries of the region, remains an unstable area, among others.

Keywords: Southeast Asia, ASEAN, Integration Process, APEC, Evaluation

\section{Introducción}

El presente artículo, versa sobre una evaluación general del proceso de integración del sudeste asiático, obviamente, de los países que conforman la subregión $^{3}$, sobre todo interesa determinar acerca de los aprendizajes y lecciones que se puedan extraer de tal espacio.

Entonces, el propósito que se busca, es analizar el cómo ha sido la integración en la subregión del sudeste asiático a través de un "examen" a los procesos de integración que se han gestado en la subregión, entre ellos la Asociación de Naciones del Sudeste Asiático (ASEAN y El Foro Económico de Asia Pacífico (APEC).

La importancia por indagar el proceso de integración, radica en que el regionalismo expresado en la integración -se origina en 1967 - con la conformación de la ASEAN, posicionando a la subregión dentro del mapa de los regionalismos y dentro de los primeros a nivel mundial.

A decir de lo anterior, la premisa de la que se parte es que a cinco décadas del inicio de la integración y cooperación del sudeste asiático, la región ha mostrado avances en materia económica, pero poco en asuntos sociales e incluso ha generado desigualdad entre los países que conforman la región.

Con el afán de comprobar o desacreditar tal premisa, se realiza una investigación documental acerca de la subregión y de su proceso, mediante artículos de revistas, capítulos de libros, libros escritos en español e inglés para, además, utilizar el enfoque histórico para analizar dicho proceso.

La estructura del contenido del artículo se compone, primero, por una contextualización de la región o subregión, donde se argumenta el origen del término sudeste asiático. Se caracteriza a los países que son parte de la región; luego, se presenta la teoría del institucionalismo liberal, a través de sus supuestos, los cuales sirven para dar explicación teórica al proceso de integración.

Además se exponen conceptos relacionados con el proceso de integración,

3 Subregión, pues forma parte del continente de Asia e incluso de otra región que se conoce como Este de Asia 
aunado a las visiones para analizar tal proceso. Tanto la funcional y la del regionalismo abierto; posteriormente, se describen algunas instituciones emanadas de tal proceso de integración. Enseguida se busca dar respuesta a la pregunta, ¿cuáles son las lecciones y aprendizajes emanados de tal proceso de integración?; y finalmente, se exponen reflexiones sobre dicho trabajo.

\section{Contextualización y caracterización del sudeste asiático}

Para Sandi y López (2007), el nombre de la región fue acuñado en el siglo XX: antes se le denominada Indias Orientales o Insulindia, haciendo referencia al subcontinente indio; subcontinente por la vasta extensión territorial.

Es también parte de lo que geográficamente se denomina Asia oriental, región del continente de Asia que se caracteriza por ser un espacio geográfico con una elevada densidad de población, tan sólo tres de los países que conforman la subregión son densamente poblados: China, Indonesia y Japón.

Además, el término sudeste asiático, fue acuñado después de la Segunda Guerra Mundial, pues antes de ella, no era de tanta importancia para los países potencias. Fue hasta que la ubicaron como una región geoestratégica para los intereses de éstas, sobre todo, para Estados Unidos y los "aliados", pues durante el periodo de 1941-1944 estaban haciendo frente a Japón, país que ocupaba la región que estaba bajo su dominio.

Es así que se distribuyen mapas de la región llamándola "Sudeste asiático", entonces para el mundo académico toma importancia con tal término. (See, Wilhelmy y Fajardo, 2007).

La subregión fue poco conocida para la colonización, los reinos de los países se organizaban por mándalas, del centro a la periferia. En la época contemporánea eso se alteró con la colonización europea de los países de la subregión, incluso las redes comerciales establecidas se desintegran con la llegada de tal colonización (See, Wilhelmy y Fajardo, 2007).

Todos los países que conforman dicha región fueron colonizados, excepto Tailandia. Alcanzaron un desarrollo económico tardío (Meza, 2011). Después de su independización, ya en el siglo XX, la región presenció guerras, movimientos insurgentes e incluso genocidios (caso Camboya), aunado a fuertes dictaduras militares (Sandí y López, 2007).

Incluso se puede decir que muchos de los países tienen gobiernos autoritarios 


\section{DOXA}

pISSN: 2395-8758

eISSN: en trámite

o son inestables, claros ejemplos de ello son Indonesia, Myanmar y Tailandia, por citar algunos.

El caso Tailandia, lo documenta Ramírez Meda en el Anuario de AsiaPacífico que editó El Colegio de México para 2017, comentando que el país pasó de ser una monarquía absoluta en 1932 a contar con 12 golpes militares consumados (el último se dio en 2014), 7 golpes fallidos en un gobierno estatista contralado por militares (Ramírez, 2017).

Por su parte Myanmar, el país de la "gente sonriente", caracterizado por contar con un gobierno socialista al estilo "burmesa" también cuenta con un gobierno que concentra la milicia (Kostzer, 2013).

Indonesia, tuvo hasta 2004 su primer gobierno democrático, y fue Susilo Bambang Yudhoyono quien por voto directo gana las elecciones en aquel país. (Hernández, 2017). Para Ivanova (2012), el desarrollo de los países del sudeste asiático tiene tres periodos de expansión, uno que llama de "largo plazo", mismo que empieza en el marco de la segunda guerra mundial, incluye la apertura comercial, así como la dominación colonial.

Un segundo que clasifica como mediano plazo, situado justo después de la segunda guerra y caracterizado por las diversas reformas que los países de dicha región implementan para hacer frente a los estragos de la guerra; el retiro de las potencias colonizadoras y por ende el inicio de su independencia. Y, finalmente, el tercer periodo que llama de corto plazo, caracterizado por el inicio del proceso de industrialización y los efectos de la crisis de 1997-1998 ocasionada en Tailandia, luego con efecto dominó en otros países de la región.

Así mismo, el sudeste asiático es un área que se caracteriza por su elevado crecimiento económico en los últimos años, pero ya con muestras de recuperación desde los sesenta para el caso de algunos países como Japón. Luego viene en escalda histórica para otros países como China, Corea del Sur, Taiwán, Tailandia, Malasia, Indonesia, Singapur, etc. (Bustelo, García y Olivié, 2004).

En general, la composición sociodemográfica de la región es heterogénea, a decir de Kostzer (2013) “... hay países donde la religión predominante y oficial es la musulmana (Brunei, Indonesia -mayor país musulmán del planeta-, o Malasia), budista (Tailandia, Myanmar o Vietnam) y católicos (Filipinas y Timor Leste)", (p. 119). Es decir, que es un mosaico religioso y no sólo eso, incluso cultural. 
pISSN: 2395-8758

eISSN: en trámite

En la actualidad el sudeste asiático alberga a 622 millones de personas distribuidas por las 11 naciones que le componen, frente a 1 billón 368 millones de China y 1 billón 260 millones de la India (Asean, 2015).

Por tanto, los países que integran al Sudeste Asiático son, Brunei, Camboya, Indonesia, Laos, Malasia, Myanmar, Filipinas, Singapur, Tailandia, Timor Oriental y Vietnam (Molina y Regalado, 2014; Vega y Hernández, 2015). Enseguida un mapa para mejor ubicación geográfica de la subregión.

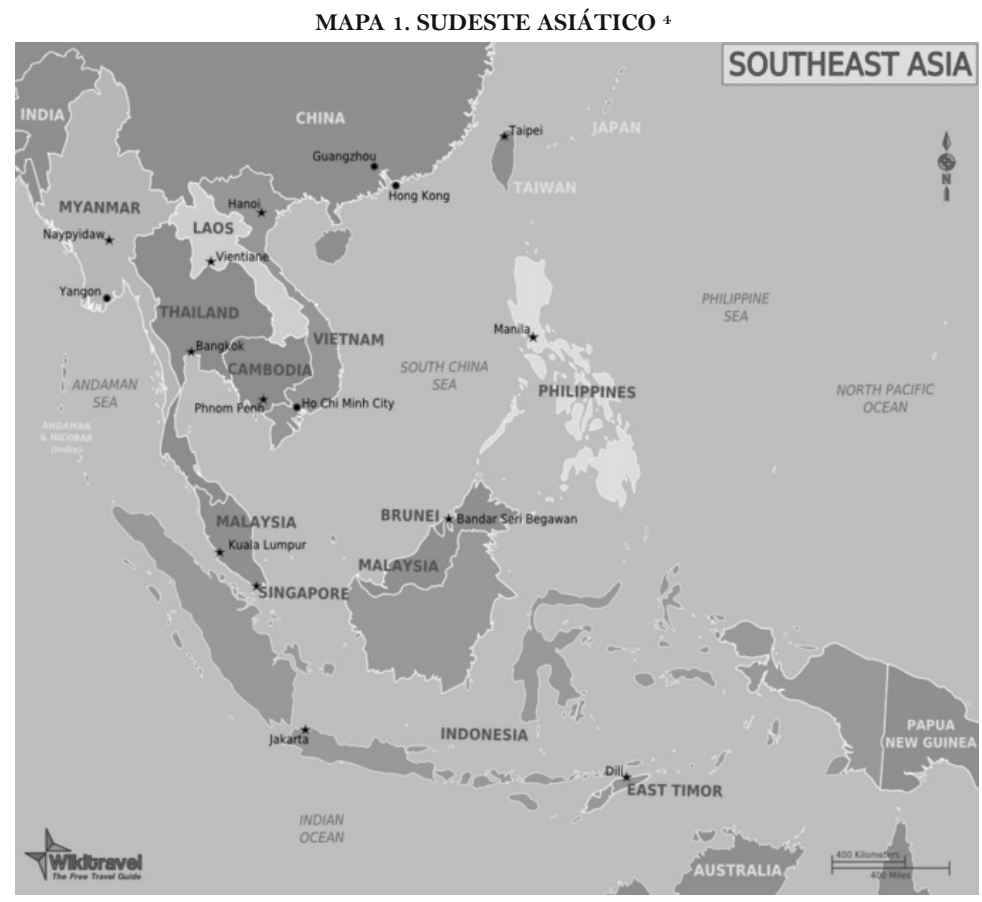

Fuente: Tomada de,https://wikitravel.org/en/File:Map_of_Southeast_Asia.png

Algunas características generales de cada uno de los once países que conforman el sudeste asiático se localizan en la tabla 1.

4. China, India, Nueva Guinea y Auralia no se consideran parte de la subregión. 
TABLA 1. CARACTERÍSTICAS DE LOS PAÍSES QUE CONFORMAN EL SUDESTE ASIÁTICO

\begin{tabular}{|c|c|}
\hline $\begin{array}{l}\text { Nombre } \\
\text { del país }\end{array}$ & Características principales \\
\hline Brunei & $\begin{array}{l}\text { Fue protectarado británico descle } 1888 \text {, su independencia se da en } 1984 . \\
\text { Cuenta con una población de } 443,593 \text { personas. } \\
\text { Su religión oficial es la musulmana. } \\
\text { Su composición étnica es de } 66 \% \text { malaya } 10 \% \text { china, indígenas y atros } \\
\text { grupos } 24 \% \text {. } \\
78 \% \text { de su población es urbana y joven ( } 64 \% \text { de la población tiene entre } 15 \text { y } \\
29 \text { años de edad). } \\
\text { Su gobierno es monárquico o sultán. } \\
\text { Su principal fuente económica es la extracción y exportación del gas natural } \\
\text { y el petróleo. Su principal socio comercial es Japón. }\end{array}$ \\
\hline Camboya & $\begin{array}{l}\text { Colonia de Francia desde } 1863 \text {, formó parte de Indochina Francesa desde } \\
1887 \text {. } \\
\text { Se independiza en } 1953 \text {, de } 1975 \text { al } 1978 \text { estuva a cargo de los Jemeres } \\
\text { Rojos, quienes realizaron genocidio en el país comandados por Pol Pot. } \\
\text { Fue invadida por Vietnam en } 1978 \text { y acupada once años. } \\
\text { Tiene una población de } 16,204,486 . \\
\text { Su composición étnica es, jemer }(97.6 \%) \text {, cham }(1.2 \%) \text { china } .1 \% \text {, vietamita } \\
.1 \% \text {. } \\
\text { El idioma oficial es el jemer. } \\
50 \% \text { de su población tiene menos de } 25 \text { años. }\end{array}$ \\
\hline Indonesia & 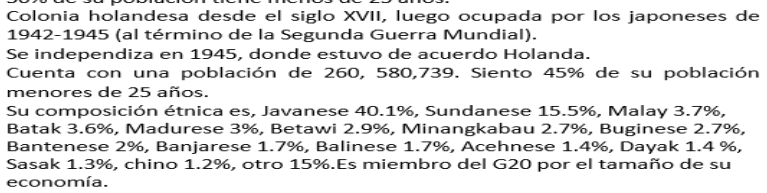 \\
\hline Laos: & $\begin{array}{l}\text { País que estuvo bajo la dominación de Tailandia hasta el siglo XVIII, ya en el } \\
\text { XIX pasó a ser parte de la colonia francesa. } \\
\text { En } 1975 \text { se pone fin a la monarquía. } \\
\text { Tiene una población de } 7,126,706 . \text { Siendo } 54 \% \text { de su población personas con } \\
\text { menos de } 25 \text { años de edad. } \\
\text { Sus principales grupas étnicos son: Lao } 53.2 \% \text {, Khmou } 11 \% \text {, Hmong } 9.2 \% \text {, } \\
\text { Phouthay } 3.4 \% \text {, Tai } 3.1 \% \text {, Makong } 2.5 \% \text {, Katong } 2.2 \% \text {, Lue } 2 \% \text {, Akha } 1.8 \% \text {, } \\
\text { otro } 11.6 \% \text {, sin embargo se estima que tenga alrededor de } 200 \text { grupos. }\end{array}$ \\
\hline Filipina: & $\begin{array}{l}\text { Archipiélago compuesto de } 7107 \text { islas que en conjunto integran } 300 \text { ooo } \\
\text { km2. } \\
\text { Hasta julio de } 2016 \text {, población estimada de } 102624209 \text {. } \\
\text { Diversidad étnica, pero sobresale tagalog ( } 28 \% \text { total de la población). } \\
\text { Idiomas oficiales filipino-tagalo y el inglés. } \\
\text { Población en su mayoría católica (Tizili, } 2017 \text { ). } \\
\text { Fue colonia espafiola en el siglo XVI, luego obtiene su independencia de } \\
\text { Estados Unidos en el } 1946 \text {. } \\
\text { Su población es de } 104,256,076 \text { personas. }\end{array}$ \\
\hline Malasia & $\begin{array}{l}\text { Población de más de } 30 \text { millones de habitantes, exactamente: } 31 \text {. } \\
381,992 \text {. } \\
\text { Se independizó de Gran Bretaña en 1957. } \\
\text { Estado musulmán moderado y democrático. } \\
\text { Etnias malaya, china e india. }\end{array}$ \\
\hline Myanmar & $\begin{array}{l}\text { Fue colonia británica, se incorpora a la India hasta } 1937 \text { que se separó. } \\
\text { En } 1948 \text { obtiene la independencia de la Comunidad Anglosajona }\end{array}$ \\
\hline Singapur & $\begin{array}{l}\text { Fue fundada por el imperio británico en 1819, luego se unió al reino de } \\
\text { Malasia en } 1963 \text {. Se independizó en } 1965 \text {. } \\
\text { Tiene una población de } 5 \text {, } 888,926 \text {. } \\
\text { Su composición étnica es de, chinos } 74.3 \% \text {, malayos } 13.4 \% \text {, indios } 9.1 \% \text {, } \\
\text { otros } 3.2 \% \text {. } \\
\text { El } 60 \% \text { tiene arriba de los } 25 \text { años. }\end{array}$ \\
\hline Tailandia & $\begin{array}{l}\text { Es el único país que no ha sido colonizado de los integrantes del sudeste } \\
\text { asiático. } \\
\text { Su reino se estableció en la mitad del siglo XIV. } \\
\text { Tiene } 68,414,135 \text { de personas. } \\
\text { Sus grupos étnicos son el thai } 97 \% \text {, el burmes } 1.3 \% \text {, otros } 1.1 . \% \\
\text { Su idioma oficial es el tailandés. } \\
69 \% \text { de la población tiene más de } 25 \text { años. }\end{array}$ \\
\hline $\begin{array}{l}\text { Timor } \\
\text { Oriental }\end{array}$ & $\begin{array}{l}\text { Colonizados por los portugueses, luego por los holandeses. De } 1942-1945 \text { fue } \\
\text { ocupado por Japón. } \\
\text { En } 1975 \text { declara su independencia de Portugal. } \\
\text { Cuenta con una población de 1, } 291,358 \text { personas. } \\
60 \% \text { de su población tiene menos de } 25 \text { años. }\end{array}$ \\
\hline Vietnam & $\begin{array}{l}\text { Conquistada por Francia de } 1858 \text { al } 1884 \text {. Luego fue parte de Indochina en } \\
1887 \text {. } \\
\text { Declaró su independencia después de la II Guerra Mundial, prero comenzó a } \\
\text { ser independiente hasta } 1954 \text {. } \\
\text { Su población es de } 96,160,163 \text { personas. }\end{array}$ \\
\hline
\end{tabular}

Fuente: Elaboración propia con datos de CIA (2017) y Tizili (2017) 
Como se puede leer y analizar de la Tabla 1, los países que forman la región del sudeste asiático tienen una diversidad de grupos étnicos, su población es relativamente joven, entre otras cuestiones, tales como los conflictos y disputas que libran entre ellos.

\section{Disputas}

Para el siguiente mapeo de disputas se utilizó la descripción que tiene CIA (2017) y nos arroja lo siguiente: El caso de Brunei y Malasia, siendo Malasia quien cede 2 concesiones de hidrocarburos a Brunei en 2010, ello por el reclamo de este último país del corredor Limbang. También tiene conflictos de extensión de límites en aguas marítimas con Vietnam.

Camboya y Tailandia tienen disputas de definición de fronteras. Al igual que con Vietnam; Camboya le acusa de realizar actividades ilegales en sus fronteras.

Indonesia tiene problemas de límites de aguas marítimas con sus vecinos.

Laos tiene problemas territoriales sobre demarcación de frontera con Tailandia y Camboya.

Filipinas tiene disputas internacionales con China y Vietnam en materia territorial.

Malasia tiene problemas de territorio sobre todo del mar con China y Filipinas, así también con Brunei.

Singapur tiene disputas con Malasia por el acceso al agua dulce, así como por cuestiones de delimitación de fronteras territoriales.

Tailandia tiene cerrada fronteras con Malasia. Problemas de frontera con Laos y Camboya, entre otros.

Timor tiene problemas de delimitación de aguas marítimas con Indonesia.

Vietnam tiene disputas con Camboya y Laos por cuestiones de cruce de armamento ilegal por las fronteras de estos dos países últimos.

En suma, se puede decir que la región es compleja al interior de los países y en sus relaciones internacionales con los vecinos de la región, sobre todo en cuestiones de poder, pero a pesar de ello mantienen intensas relaciones económicas, razón que nos tiene en este análisis. 


\section{Nota metodológica y teórica para el entendimiento de la integración}

Este artículo es producto de una revisión documental sobre lo que se ha escrito del sudeste asiático en materia de integración, por tanto en su mayor parte es descriptivo, debido a que busca definir el cómo del proceso de integración, con los resultados empíricos que ha originado en los países de la subregión.

Así mismo, como el nombre lo indica, se busca evaluar a manera de "examen" las particularidades de los procesos de integración que ha tenido dicha subregión, sin embargo, para tener parámetros a evaluar, primero se requiere revisar qué se entiende por integración. Esta palabra se concibe desde algunos enfoques teóricos denominados funcionalismo y nuevo regionalismo, mejor conocido este último como regionalismo abierto.

También, al proceso de integración le acompañan conceptos como el de cooperación, pues sin las acciones de los Estados, de manera articulada en pro de un bien u objetivo en común no podría haber integración, por lo que, tal cooperación se concibe desde las teorías liberales; una de ellas es la del institucionalismo neoliberal, que da importancia a las instituciones como articuladora del proceso de cooperación primero y luego de integración.

El institucionalismo entonces, se entiende a decir de Anaya (2014) en dos sentidos, el papel de las instituciones internacionales, a pesar de que los Estados son los actores centrales del sistema internacional; y otra, que a pesar de que las preferencias de los Estados son fijas, éstas no se limitan a ser preferencias relativas o a la supervivencia dentro del sistema (p.27).

Para los institucionalistas neoliberales la cooperación es posible, sobre todo les interesa la cooperación en materia económica, he aquí una de las razones del porqué se eligió esta teoría para fundamentar lo que pasa con el proceso de integración del sudeste asiático, pues como iremos viendo, no se puede hablar de un proceso en el sentido funcionalista al estilo Unión Europea, sino en el sentido más de aspectos de libre mercado, acuerdos comerciales, ni siquiera de mercado común.

Además, “... los Estados buscan ganancias absolutas; es decir, su objetivo es maximizar su beneficio, independiente de que los demás Estados participen en los procesos de cooperación ganen más que ellos" (Anaya, 2014, p. 28).

Por otro lado, la teoría antes mencionada, sólo se enfoca a los Estados y a las instituciones, dejando de lado a otros actores del sistema internacional, tales 
como a empresas, individuos con capacidad de influencia, grupos de presión dentro del análisis de la cooperación e integración.

Por lo que es menester evocar a la teoría de la interdependencia, la cual es una corriente del liberalismo que explica cómo funciona la política mundial cuando hay interdependencia en aumento por parte de los actores del sistema internacional, dentro de estos están los Estados, pero justo esta teoría reconoce a otros, dando cavidad a organizaciones internacionales, empresas transnacionales, grupos de interés, y demás. (Schiavon, 2014).

La lógica de las ganancias por parte de los actores que cooperan, ya sean países, organizaciones internacionales, empresas y otros es la de ganancias absolutas bajo la fórmula suma positiva, es decir, que prefieren ganar algo que nada, no les importa que el otro o los otros ganen más dentro de los resultados de la cooperación (Schiavon, 2014).

En cuanto al concepto como tal de integración, se refiere a los cambios que se dan entre unidades políticas más o menos soberanas (países) que interactúan en el sistema internacional con relaciones internacionales constantes (Palomares, 2015).

Para Ernst Hass, la integración es “...el proceso por el cual los actores políticos en diversos y distintos ámbitos nacionales aceptan desviar sus lealtades, expectativas y actividades políticas hacia un nuevo centro, cuyas instituciones poseen o demandan jurisdicción sobre Estados nacionales (En Palomares, 2015, p. 343).

Desde la lógica del funcionalismo, sobre todo desde las visiones clásicas de integración económica, que a su vez se vincula al estudio del comercio internacional enfocado a las uniones aduaneras, el proceso de integración tiene varias etapas (Palomares, 2015), mismas que se presentan en el siguiente cuadro. 
TABLA 2. ETAPAS DEL PROCESO DE INTEGRACIÓN

\begin{tabular}{|c|c|c|c|c|}
\hline Etapa & Zona librecambio & Unión Aduanera & Unión económica & Integración total o Unión total \\
\hline Característica & $\begin{array}{l}\text { Área que se forma por varios } \\
\text { páses. Se eliminan aranceles } \\
\text { aduaneros y toda restricción } \\
\text { comercial, se mantiene un arancel } \\
\text { frente al exterior. }\end{array}$ & $\begin{array}{l}\text { Aliade a las caracteristicas del libre } \\
\text { comercio un arancel aduanero } \\
\text { único frente a otros, suprime el } \\
\text { problema de la entrada de } \\
\text { mercancías por el miembro de } \\
\text { menor arancel. }\end{array}$ & $\begin{array}{l}\text { e se forma cuando los que lo sigue al mercado común, pues le } \\
0 \text { integran añaden a la unión agrega cierto grado de } \\
\text { a aduanera la franquicia para la armonización de politicas } \\
\text { e circulación de los factores de económicas, para eliminar las } \\
\text { e producción, es decir que hay disparidades entre los países que lo } \\
\text { movilidad de factores de capital y integran. } \\
\text { trabajo. }\end{array}$ & $\begin{array}{l}\text { Va más allá de las pollticas } \\
\text { económicas, sino que interesa la } \\
\text { unificación de politicas monetarias, } \\
\text { políticas fiscales, sociales, entre } \\
\text { otras. }\end{array}$ \\
\hline
\end{tabular}

Fuente: Elaboración propia con información de Palomares (2015, pp. 348-349).

Cabe mencionar, que así como existe la visión clásica de la integración, existen otras visiones que analizan la integración, entre ellas se puede localizar al regionalismo discutido, también conocido como nuevo regionalismo o regionalismo abierto; noción que se origina a la par del incremento de los procesos de globalización, sobre todo de su homogeneización económica y comercial que se daba a finales de los $80 \mathrm{~s}$ y principios de los 90 s.

Entonces esta visión que se focaliza en asuntos económicos, comerciales y financieros, puede ayudar mucho más a entender la integración en el sudeste asiático; sin olvidar que muchas veces se toma como modelo de referencia al proceso de integración de la Unión Europea, que justo va en el sentido del proceso clásico (Palomares, 2015).

Esta visión de regionalismo abierto pone en el centro de la integración la interdependencia entre quienes forman parte del ente supranacional, bloque o región, en el sentido de que adoptan una serie de políticas tendientes a elevar la competitividad internacional en materia económica.

En este sentido son los países los que deciden qué medidas adoptar para mejorar su integración con la región y esta a su vez ser competente como bloque a nivel en el complejo sistema internacional.

Esta visión no permite criterios supranacionales para corregir los efectos que se pueden ocasionar al interior de los países una vez sumándose al bloque que compite en la economía mundial, pues la rapidez del mercado y sus efectos pueden originar desigualdades inmediatas. Por tanto se puede concluir que es una manera de integración pragmática.

Finalmente, se propone, para realizar la evaluación a la integración del sudeste asiático que se revise con dos lentes (las dos visiones aquí analizadas 
de integración) el proceso de integración de la región.

Se analice qué etapas de la visión clásica de integración ha cumplido el sudeste asiático a través de sus iniciativas de integración, sobre todo de ASEAN y APEC; y desde el enfoque de regionalismo abierto, ¿qué resultados se han producido con el pragmatismo en materia económica para los países que integran la región?, estos últimos sean positivos y negativos.

\section{La integración del sudeste asiático, revisión desde el proceso de institucionalización de la ASEAN}

El término de la Segunda Guerra Mundial es un periodo clave para entender el despegue económico del sudeste asiático como elemento catalizador de la integración de los países que conforman la región.

Porque por un lado, Japón tenía contralada la zona entre 1941-1944 y fue justo un espacio común para que los países coexistieran baja el mismo régimen ocupacional. See, Wilhelmy y Fajardo (2007), coinciden en que esta ocupación promovió una "conciencia regional antioccidental", misma que no duró mucho, pues al ser el país nipón un vencido de la guerra tuvo que retirarse de la zona.

En el mismo sentido del párrafo anterior, se presenta, la idea de que Estados Unidos debido al inicio de la Guerra Fría y por ende el inicio de un orden internacional "bipolar" 5 , como estrategia para hacer frente al comunismo, se interesó más por la región como espacio geopolítico.

Otro suceso, fue la Federación de Malasia, donde se decide integrar a Malasia y a Singapur, en una sola federación en 1963, sin embargo, esta iniciativa no perduró, para 1965 Singapur ya había declarado de nuevo su autonomía. (Sadí y López, 2007).

Un primer intento de integración de la región de manera supranacional la Organización del Sudeste de Asia (SEATO), misma que fue facilitada por Estados Unidos e ingresaron Tailandia y Filipinas, pero tal organización no funcionó (Bartesaghi, 2014 y See, Wilhelmy y Fajardo, 2007).

5 Bipolar en el sentido de que, el sistema internacional estaba ordenado por dos "polos de poder", Estados Unidos y los aliados y la Unión de Repúblicas Socialistas Soviéticas (URSS), que marcó un hito en el marco de la Guerra Fría por ser un enfrentamiento ideológico en primera y en segunda se libran batallas por otros países pero con apoyo de estos dos polos de poder de aquel entonces. 


\section{DOXA}

pISSN: 2395-8758

eISSN: en trámite

Luego, Bartesahi (2014) documenta un antecedente del ASEAN impulsado por países que le integran. Fue la extinta Asociación del Sudeste de Asia (ASAS), donde se localiza la participación de Filipinas y Tailandia, luego se incorpora a Malasia.

Con el panorama antes descrito nace la Asociación de Naciones del Sudeste Asiático (ASEAN por sus siglas en inglés) en 1967, que en principio busca ser una respuesta a la inestabilidad en materia de seguridad entre los países de la región. En la memoria colectiva universal perduran los conflictos de Vietnam y Camboya.

La iniciativa para la creación de la ASEAN fue de Tailandia, Malasia y Filipinas, países que creían que la cooperación regional podría coadyuvar a mejorar la confianza recíproca de las naciones de la región, al igual que a pacificar.

Posteriormente, reunidos en Bangkok, las tres naciones antes dichas, más Indonesia y Singapur, aprueban la Declaración de Bangkok, misma que buscaba no sólo pacificar la zona, sino potencializar el crecimiento económico (a futuro), mejorar la cuestión social, estimular el desarrollo cultural, entre otros asuntos. (See, Wilhelmy y Fajardo, 2007).

Plaza (1995) comenta que la ASEAN surge como foro regional de cooperación para promover el reparto de la ayuda que Estados Unidos estaba inyectando en la zona, obviamente como estrategia geopolítica para impedir la expansión del comunismo. Songhi, estudioso indio (2007) por su parte menciona que la integración del sudeste fue de las primeras a nivel mundial, textualmente menciona:

Integration in Asia has a long history, starting with the formation of Association of Southeast Asian Nations (ASEAN) in 1967. Originally, ASEAN was seen more as a platform for regional import a substitution than a free trade area. With the ending of the Cold War in the early 1990s, ASEAN was able to pursue the formation of the ASEAN Free Trade Association (AFTA), with the aim of accelerating trade within the Southeast Asian region. (p. 326).

Para Ignacio Bartesaghi, la ASEAN también es el acuerdo más exitoso para el continente asiático. Comenta que es la zona más rica del mundo, tiene importancia geoestratégica por las rutas comerciales que atraviesan la región (2014, pp.1-2).

Como se dijo en párrafos anteriores, en principio la ASEAN buscaba una 
pISSN: 2395-8758

eISSN: en trámite

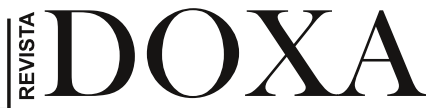

estabilidad política y de defensa de la región, bajo los principios de independencia, igualdad, integridad territorial e identidad nacional de los países, eso fue importante en su nacimiento, por las múltiples disputas territoriales y desconfianza que se vivía en la zona. (Bartesaghi, 2014).

Un segundo momento importante para la ASEAN como organismo internacional que buscaba la seguridad fue la Declaración sobre la Zona de Paz, Libertad y Neutralidad (ZOPFAN), pretendía hacer frente a las bases extranjeras que para 1971 todavía existían en algunos países del sudeste asiático, por ejemplo en Indonesia (See, Wilhelmy y Fajardo, 2007).

Otro evento que evidencia la relevancia de mantener sin conflicto la región se da en la conferencia que se celebra en Bali en 1976, por parte de los miembros de la ASEAN, puesto que se formaliza un pacto de no agresión entre sus miembros; pero dos años más tarde (1978) el conflicto de Vietnam Camboya polarizó a la organización.

A lo que ha salido avante, ya que la mediación diplomática tal conflicto, es uno de sus mayores éxitos, con ello se comprueba el éxito de la organización, la razón de ser en aquel entonces (See, Wilhelmy y Fajardo, 2007; y Bartesaghi, 2014).

Para esas fechas, la ASEAN ya tenía más institucionalidad, en este caso debido a que contaba con una Secretaría de la ASEAN, pero contó con sede hasta 1981. En 1984 con el fin de incorporar más miembros a la organización, la estrategia a seguir fue ASEAN 6, que buscaba incorporar a Camboya, Laos, Myanmar y Vietnam, pero sólo ese año se incorpora Brunei, luego Vietnam en 1995, posteriormente Myanmar (1997) y Camboya hasta 1999 (Ferrando, 2013 y Bartesaghi, 2014).

Esto no quiere decir que no hubo eventos importantes ante la incorporación de uno u otro país, todos coincidían en tener como eje rector la seguridad de la región; entonces se puede argumentar que desde la creación en la mitad de la década de los 60s hasta la década de los 80s, la ASEAN, se institucionalizó.

A decir de Molina y Regalado (2014, p. 7), durante los 60-70s, "tuvo logros significativos donde prevalece el multilateralismo, la cooperación regional, en ese periodo tuvo más motivaciones políticas que económicas".

Luego a dicho proceso de integración que en principio era político - de defensa para lograr estabilidad en la región, se apareja el fenómeno de liberalización comercial que impacta en las economías asiáticas, en particular 


\section{DOXA}

pISSN: 2395-8758

eISSN: en trámite

en los países de Indonesia, Malasia y Tailandia, luego en Filipinas ${ }^{6}$, las economías de estas naciones crecen mucho, gracias al acelerado proceso de industrialización. (Bustelo, García y Olivié, 2004).

Ya en los 90s, la integración regional toma más impulso y se volcó hacia los asuntos comerciales, propiciado por la buena racha económica por la que pasaban los países de la región, se estaban expandiendo. Por ejemplo, para 1992 se firma por parte de Brunei, Indonesia, Filipinas, Malasia, Singapur y Tailandia el área de libre comercio, misma que entra en vigor en 1993 (Ferrando, 2013; Bartesaghi, 2014 y Bustela, Garcia y Olivié, 2004), al mismo tiempo se firman los tratados de París que ponen fin al conflicto iniciado por Vietnam por su invasión a Camboya.

Siguiendo con el recuento histórico de los eventos importantes que han marcado a la ASEAN, el contexto en que se desarrollan los eventos que llevan a la organización a la consolidación en pro de facilitar el comercio entre las naciones que le integran y entre la organización y el mundo, es un contexto de liberalización económica y por tanto es menester presentar la estrategia que siguieron los países de la ASEAN para integrarse a la economía mundial como un bloque.

Entonces se crea la figura ASEAN +, es decir la Asociación firma acuerdo con tales o cuales países. Para 1997, se da la ASEAN + 3 (China, Japón y Corea del Sur); en 2002 ASEAN + 1 (China), pero sólo los países fundacionales con China en un principio.

Luego hacia el 2010 se extendería a Vietnam, Laos, Myanmar y Camboya. En 2005 también se da algo parecido al caso chino, pero con Corea del Sur; luego pasó a ser de servicios en 20017, posterior en 2009 a la liberalización de inversiones. Para 2010 se buscó crear un área de libre comercio entre los seis miembros y Corea; para el periodo 2016-2018 se incluirán los demás.

En 2008 se comienza a negociar un acuerdo más amplio entre Japón con la ASEAN, por supuesto como contrapeso a la iniciativa China. India también tiene acercamientos con la ASEAN, iniciando en 2003 y terminando en 2009. Finalmente se busca una Asociación Económica Integral del Este de ASIA, que incluya al ASEAN, a la ASEAN + 3, más Australia, Nueva Zelanda y la India, como un esfuerzo disfrazado para hacer contrapeso a la balanza de

6 A pesar de ser en menor medida, este país durante 1980 logró implementar reformas para la liberalización comercial (Tlizi, 2007). 
poder de la locomotora china. Tiene tres pilares, el económico, sociocultural y el de seguridad (Bustelo, García y Olivié, 2004).

Como se pudo leer, este recuento histórico de sucesos relevantes han marcado el proceso de integración del sudeste asiático, sobre todo se deduce lo comentado por muchos especialistas: de ser una asociación para coadyuvar las tensiones de desconfianza en la región, pasó a ser un área pujante en materia de libre mercado, liberalización comercial, y demás.

\section{Foro APEC.}

El APEC, nace en 1989, justo en la pujanza económico-comercial de los países del sudeste asiático, para dialogar sobre temas económicos, en específico de comercio, inversión, tecnología, empleo, entre otros. Sus iniciadores fueron los países de la ASEAN, junto a Japón y Australia. (Wilhelmy, 2012).

Posteriormente, se le suman países de la Cuenca del Pacífico, aunado a un tumulto de empresarios. Cabe mencionar que el Foro no tenía un plan a seguir, por ello que se diseña una "hoja de ruta" por parte de un grupo de eminentes expertos en la materia, es así que el APEC, es un foro que poco a poco se convierte en una organización internacional clásica, con múltiples temas a discutir. Sondhi (2007) refiere, "APEC has had impressive successes and some failures, mainly as a result of limited institutional development." (p. 327).

\section{Somera evaluación del proceso de integración desde la visión del regionalismo abierto y el funcionalismo (teoría clásica de integración)}

Una vez revisado el proceso de integración del sudeste asiático mediante el avance institucional de la ASEAN, es conveniente realizar el "examen" que pretende este trabajo de investigación.

Si bien, los procesos de globalización han funcionado como estímulo para incentivar los procesos de regionalización, ya que, por ser una unidad menor en el sentido de tamaño, es más viable de construir, sobre todo en materia económica. La integración regional impulsa la creación y potencialización de instituciones internacionales compuestas por países, así la ASEAN ha salido 


\section{DOXA}

pISSN: 2395-8758

eISSN: en trámite

avante. (Cuadra, 2000).

En principio logra su cometido, contener la inestabilidad de la región y coexistir en un ambiente turbulento azotado por conflictos internos dentro de los países que conforman la región en el marco de la Guerra Fría; los acuerdos de París que de alguna forma pone fin al conflicto VietnamCamboya, es un claro ejemplo de ello.

Sin embargo, siguen latentes tensiones en la región, claro ejemplo son los desacuerdos entre Vietnam y Filipinas con China por enfrentamientos de embarcaciones (Bartesaghi, 2014); como se vio en el capítulo de contextualización de la región, sigue habiendo ciertas disputas de delimitación de fronteras, sobre todo en alta mar.

La región hizo frente a una crisis económica en 1997-1998, iniciada en Tailandia, fue una burbuja económica, ello arrastró consigo a muchos de los países del este asiático, al reventar la burbuja financiera cayeron en recesión (Kostzer, 2013).

Claro ejemplo de tal debilitamiento económico fue el caso Indonesia (país más poblado de la región), que estuvo a punto de caer en una fragmentación interna por el agravamiento económico. Se independizó Timor Oriental en 1999 (Hernández, 2017).

Para Ivanova et al (en J Pempe, 1997):

"Dicha crisis afectó aún más el comercio intrarregional y dificultó la salida de la recesión por parte de Japón, sobre todo ante la desaceleración que experimentó Estados Unidos, su principal socio, a pesar de ello, Japón ha sido visto como el motor regional en cuanto a diversificación, inversión e integración: la dependencia de los países asiáticos con respecto a Japón es significativa, el setenta por ciento de la ayuda exterior de Japón va hacia Asia, y son las inversiones japonesas en la región las que marcan la pauta para su desarrollo y su crecimiento (2012, p.39)".

Entonces, la región logró salir avante de la crisis, profundizando su proceso de integración, pues se utiliza el pragmatismo como elemento central del proceso y se focalizan las políticas públicas internacionales para lograr los objetivos que se han planteado como región (Bartesahi, 2014). Así que, se tiene un "modelo" de desarrollo para tal cometido. 
pISSN: 2395-8758

eISSN: en trámite

TABLA 3. "MODELO DE DESARROLLO DEL SUDESTE ASIÁTICO (POLÍTICAS ECONÓMICAS)”.

\begin{tabular}{|c|c|c|c|c|}
\hline Rasgo en común & Política económica consistente & $\begin{array}{c}\text { Crecimiento económico ágil y } \\
\text { distributivo }\end{array}$ & Promoción al capital humano & Sector agrícola \\
\hline Características & $\begin{array}{l}\text { A pesar de ser economías } \\
\text { endeudadas, su endeudamiento } \\
\text { fue manejado en todo momento. } \\
\text { Respecto a la inversión, las } \\
\text { economías manejaron tasas de } \\
\text { interés positivas, esto es } \\
\text { importante para dar certidumbre } \\
\text { al sector privado. }\end{array}$ & $\begin{array}{l}\text { Tanto, paises de mayor renta } \\
\text { como los de menor de la región } \\
\text { en cuestión, distribuyen el } \\
\text { ingreso de manera equitativa, } \\
\text { mismo que trajo consigo } \\
\text { mejores en calidad de vida de } \\
\text { la sociedad. }\end{array}$ & $\begin{array}{l}\text { El Sudeste Asiático ha invertido en } \\
\text { la mejora del capital humano de } \\
\text { sus habitantes, lo cual se realiza al } \\
\text { principio del crecimiento } \\
\text { económico de sus economías; } \\
\text { resultando en movilidad social, } \\
\text { incorporación de las mujeres a la } \\
\text { educación. }\end{array}$ & $\begin{array}{l}\text { Las economías de esta región no despreciaron el } \\
\text { potencial de este sector, a diferencia de otras } \\
\text { regiones del globo que le daban importancia al } \\
\text { sector industrial, olvidándose del sector en cuestión, } \\
\text { entonces se realizan reformas sobre tenencia a la } \\
\text { tierra, infraestructura. Ello trajo consigo que el } \\
\text { salario rural se moviera a la par que el salario } \\
\text { urbano. }\end{array}$ \\
\hline
\end{tabular}

Fuente: Elaboración propia con información de Sandiz y López (2007, pp. 370-372).

Por otro lado, una de las estrategias que se ha utilizado para el desarrollo del capitalismo de la región, es “Ánades volantes", definido como proceso gradual de especialización productiva y de redespliegue industrial en el área (Molina y Regalado, 2014, p. 3).

En tal proceso Japón ha servido mucho a la región, pues es quien va a la cabeza en el proceso, después viene el derrame hacía los "cuatro tigres asiáticos"-Corea del Sur, Taiwán, Singapur y Hong Kong- clasificados de reciente industrialización, ellos a sus vez, derraman o gotean su excedente a otros, en este caso son los vecinos de Malasia, Tailandia e Indonesia, así se va repitiendo la estrategia hasta incluir a China y Vietnam. Todo esto se conoce como el "milagro asiático" (Ibid).

En suma, se puede decir desde la visión del regionalismo abierto, que el sudeste asiático es una región integrada y que tiene elementos para demostrar, entre ellos la cantidad de acuerdos que ha firmado con sus vecinos regionales, caso Japón, China, Corea del Sur, India, entre otros, al igual que estos vecinos han deslocalizado su producción en los países de la ASEAN, entonces es recíproco el asunto.

Por lo que respecta a la visión clásica de integración, apliquemos las etapas de la tabla 2, a manera de "check list" para ver si el proceso de integración que se anda evaluando ha cumplido con los pasos, con el fin de saber si aún le falta camino por recorrer para ser un proceso pleno de integración.

Las etapas son: Zona de libre cambio, luego Unión Aduanera, Marcado Común, Unión económica e integración total o Unión total. La pregunta es, ¿cumple o no la ASEAN como proceso de integración más representativo del sudeste asiático los pasos para la integración formal al estilo Unión Europea?

Vol. 8 Núm. 14 Enero - Junio 2018 
Entonces a revisar:

TABLA 4. EXAMEN SOMERO AL PROCESO CLÁSICO DE INTEGRACIÓN DEL SUDESTE ASIÁTICO A TRAVÉS DE LA ASEAN

\begin{tabular}{|c|c|c|c|c|c|}
\hline Etapa & $\begin{array}{c}\text { Zona } \\
\text { librecambio }\end{array}$ & $\begin{array}{c}\text { Unión } \\
\text { Aduanera }\end{array}$ & $\begin{array}{l}\text { Mercado } \\
\text { común }\end{array}$ & Unión económica & $\begin{array}{c}\text { Integración } \\
\text { total o Unión } \\
\text { total }\end{array}$ \\
\hline Característica & $\begin{array}{l}\text { Área que se } \\
\text { forma por } \\
\text { varios } \\
\text { países. Se } \\
\text { eliminan } \\
\text { aranceles } \\
\text { aduaneros y } \\
\text { toda } \\
\text { restricción } \\
\text { comercial, } \\
\text { se } \\
\text { mantiene } \\
\text { un arancel } \\
\text { frente al } \\
\text { exterior. }\end{array}$ & $\begin{array}{l}\text { Añade a las } \\
\text { característic } \\
\text { as del libre } \\
\text { comercio un } \\
\text { arancel } \\
\text { aduanero } \\
\text { único frente } \\
\text { a otros, } \\
\text { suprime el } \\
\text { problema de } \\
\text { la entrada de } \\
\text { mercancías } \\
\text { por el } \\
\text { miembro de } \\
\text { menor } \\
\text { arancel. }\end{array}$ & $\begin{array}{l}\text { Se forma } \\
\text { cuando los } \\
\text { que lo } \\
\text { integran } \\
\text { añaden a la } \\
\text { unión } \\
\text { aduanera la } \\
\text { franquicia } \\
\text { para la } \\
\text { circulación } \\
\text { de los } \\
\text { factores de } \\
\text { producción, } \\
\text { es decir que } \\
\text { hay } \\
\text { movilidad } \\
\text { de factores } \\
\text { de capital y } \\
\text { trabajo. }\end{array}$ & $\begin{array}{lr}\text { Sigue al } & \text { mercado } \\
\text { común, pues le } \\
\text { agrega cierto } \\
\text { grado } \\
\text { armonización de } \\
\text { políticas } \\
\text { económicas, para } \\
\text { eliminar las } \\
\text { disparidades entre } \\
\text { los países que lo } \\
\text { integran. }\end{array}$ & $\begin{array}{l}\text { Va más allá de } \\
\text { las políticas } \\
\text { económicas, } \\
\text { sino que } \\
\text { interesa la } \\
\text { unificación de } \\
\text { políticas } \\
\text { monetarias, } \\
\text { políticas } \\
\text { fiscales, } \\
\text { sociales, entre } \\
\text { otras. }\end{array}$ \\
\hline Cumple & Sí & Sí & $\begin{array}{c}\text { Si, de } \\
\text { manera } \\
\text { parcial }\end{array}$ & NO & NO \\
\hline Comentario & $\begin{array}{l}\text { Si, existe un } \\
\text { tratado } \\
\text { para tal } \\
\text { cometido. }\end{array}$ & $\begin{array}{l}\text { Están casi } \\
\text { suprimidos } \\
\text { en los países } \\
\text { que } \\
\text { conforman la } \\
\text { región. } \\
\text { Tienen } \\
\text { políticas en } \\
\text { común, sin } \\
\text { embargo } \\
\text { hace falta } \\
\text { trabajarlas } \\
\text { mejorarlas y } \\
\text { aplicarlas en } \\
\text { los países al } \\
\text { interior }\end{array}$ & $\begin{array}{l}\text { Algunos, la } \\
\text { idea es para } \\
2020 \text { llegar } \\
\text { a un } \\
\text { mercado } \\
\text { común, } \\
\text { dista aún } \\
\text { mucho para } \\
\text { ello. }\end{array}$ & $\begin{array}{l}\text { Hay políticas } \\
\text { macroeconómicas } \\
\text {, pero no en el } \\
\text { sentido monetario } \\
\text { como el caso de la } \\
\text { "zona euro". }\end{array}$ & $\begin{array}{l}\text { Por supuesto } \\
\text { que están } \\
\text { lejos de esto, } \\
\text { de homologar } \\
\text { salarios, } \\
\text { seguridad } \\
\text { social, etc. } \\
\text { Incluso hay } \\
\text { desigualdades. }\end{array}$ \\
\hline
\end{tabular}

Fuente: Elaboración propia con base en las fuentes revisadas. 
En suma, coincidiendo con Bartesaghi (2014), "Clasificando a la ASEAN de acuerdo a una de las categorías habitualmente utilizadas por la teoría clásica de integración, el proceso podría catalogarse como una zona de libre comercio pero en vías de transformarse en un mercado común (previsto para 2015)." (p. 13).

Entonces viendo la tabla 4 de evaluación somera, se puede argumentar que desde dicha visión tradicional emanada del comercio internacional, apenas van en la mitad o antes de la mitad el proceso de integración.

Tampoco es nada despreciable, quizás estos países no quieren llegar a ser Unión Europea, tiene un pensamiento pragmático en materia de política exterior, al interior tienen muchos problemas de desarrollo.

\section{Aprendizajes y lecciones del proceso de integración}

Como nos muestra la historia a través de la historiografía, los intentos por integrar el sudeste asiático en organizaciones o instituciones supranacionales es de gran calado a nivel internacional, claro ejemplo de ello es la ASEAN, que justo este 2017 cumple ya sus 40 años desde la Declaración de Bangkok en 1967.

Y entre los principales aprendizajes y lecciones que se destacan como resultado de la investigación documental que se realiza para este artículo, son los siguientes:

1. El enfoque gradualista (Plaza, 1995) con que se ha desarrollado dicho proceso de integración, impulsado por las estrategias de desarrollo del capitalista en las naciones del sudeste asiático, teniendo como principales polos de derrame a Japón, Corea del Sur, Hong Kong, Taiwán, ahora ya la China popular.

2. Tiene lazos informales que permiten que sea una integración silenciosa, que a decir de Molina y Regalado, “...los esquemas no son impulsados por los gobiernos e instituciones regionales vinculadas con el desarrollo (...) sino que la integración debe sus esfuerzos coordinadores al sector empresarial" (2014, p. 5).

3. El Banco Mundial en 1993 reconoce la estabilidad 
macroeconómica de la región, a la burocracia de los países que le integran, a los grupos de presión y demás (Bustelo, García y Olivié, 2004).

4. Salieron delante de la crisis financiera de 1997-1998, incluso profundizaron lazos, más que generar desunión y mayor desconfianza.

5. El uso del pragmatismo es un aprendizaje-lección conveniente, pues si bien, es una región heterogénea, con múltiples conflictos al interior de los países que le conforman, a pesar de ello generan crecimiento económico, pueden dialogar al "estilo ASEAN".

6. Se posicionan en bloque en eventos internacionales, a diferencia de otros esfuerzos de integración como Mercosur, entre otros, dónde los países van de manera individual, sin una estrategia en común.

Seguramente hay muchas más lecciones y aprendizajes que podemos extraer del proceso de integración al estilo regionalismo abierto que sucede en el sudeste asiático.

\section{Reflexiones finales}

En el trabajo documental que se realizó para este texto, se puede constatar las múltiples fuentes que hablan sobre la región; entonces hacerse una idea de ella con tanta información disponible puede ser una ventaja, en el sentido de la disposición de información, pero también un problema, pues hay mucho que analizar, entonces se puede caer en la dispersión.

El trabajo cumple con el objetivo propuesta, de evaluar a manera de examen el proceso de integración a través de la ASEAN, fue somero pero importante, pues se hace desde la visión del proceso clásico de integración y desde el enfoque del nuevo regionalismo.

Otras reflexiones surgidas son que entonces, tanto Malasia como Singapur son las estrellas del Sudeste Asiático, ambas fueron colonias del Imperio Británico, tendrá que ver en su economía de mercado, claro, con dosis de autoritarismo. Así también ambas intentaron integrarse en una sola Federación pero no lo lograron, más tarde se crea la ASEAN, ¿eso ayudaría? 
El proceso de integración en la región trae consigo el aumento de las desigualdades en la región, pues en unos países existe movilidad social, caso Singapur y en menor medida en Malasia, y en otros siguen persistiendo pobreza, desigualdades, caso Indonesia, Filipinas, Camboya, Myanmar, Laos; entonces, ¿el derrame económico que tanto clasifica a la región es sólo para unos pocos?

La región sigue siendo inestable, en materia de conflictos internos, conflictos religiosos, caso Myanmar con los roghinyá; sigue habiendo violación a los derechos humanos, persiste la censura, grupos terroristas; ahora se incrementan más los riesgos de algún desastre natural debido al cambio climático que puede impactar en la zona.

Sin embargo, los temas antes enunciados, pueden ser insumo para otras investigaciones en un futuro no muy lejano.

\section{Referencias}

Anaya, M. A. (2014). Teoría de Relaciones Internacionales. En Los derechos humanos en y desde las Relaciones Internacionales, pp.21- México: CIDE

Asean (2015). ASEAN ACCS Final. Recuperado de, https://www.youtube.com/watch?v=_JFoNYlwwDQ\&feature=yo utu.be

Bartesahi, I. (2014). La Asociación de Naciones del Sudeste Asiático: algunas similitudes con la Unión Europea. Recuperado de, http://ucu.edu.uy/sites/default/files/pdf/2015/asociacion_nacion es_sudeste_asiatico_similitudes_union_europea.pdf

Bustelo, P., García, C. y Olivié, I. (2004). Estructura económica de Asia Oriental. Madrid, España: Ediciones Akal.

Casa Asia (s/f). Asociación de Naciones del Sudeste asiático. Recuperado de, https://www.casaasia.es/triangulacion/organiz/asean.pdf

Central Inteligence Agency (CIA) (2017). Revised in, https://www.cia.gov/library/publications/the-worldfactbook/geos/bm.html

Cuadra, M. H. (2000). Globalización y mercados emergentes en los noventa. Crisis financiera en México y el Sudeste Asiático (Tesis de maestría). Colima, México: Universidad de Colima. Ferrando, A. (2013). Asia Oriental y Sudeste Asiático: de la ASEAN al 


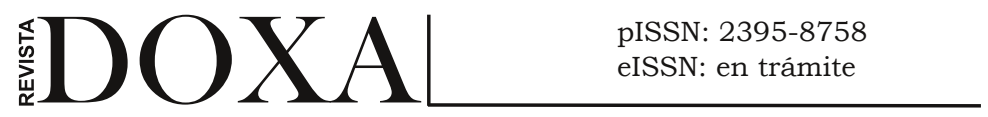

RCEP. En Comercio Internacional. Argentina: Instituto de Estrategia Internacional.

Hernández, S. F. (2017). Indonesia. Anuario de Asia Pacífico, pp. 337-386. México: El Colegio de México. Ivanova, A; Rangel, E; Celaya; R. y Gámez, A. (2012). II. Asia del Este y del Sureste: Las experiencias concretas de desarrollo económico. En APEC: más allá del comercio, pp-35-54.. México: Comisión de Relaciones Exteriores Asia Pacífico, LXI Legislatura del Senado de la República; UABCS y Universidad de Colima.

Kostzer, D. (2013). Myanmar, Burma, Birmania: El camino a recorrer del último dragón. En Revista Estado y Políticas Públicas, (1), (pp.115122).

Martin, J. y Smith, M.L.R. (2006). ASEAN and East Asia- International Relations. London: University of London.

Meza, L. J. (2011). Escenario regional de Asia y Oceanía. México: UABC. Molina, D. E. y Regalado, F. E. (2014). Integración económica en AsiaPacífico. Evolución y perspectivas. CIEI- Centro de Investigaciones de

Economía

Internacional.

Palomares, L. G. (2015). Conceptos y teorías de la integración. En Del Arenal, C. y Sanahuja, J. A. (coords.), Teorías de las relaciones internacionales,

pp.329-357.

Plaza, C. S. (1995). La ASEAN: proyecto de integración económica en el Sudeste Asiático. En Comercio Exterior.

Ramírez, M. K. (2017). Tailandia. En Anuario Asia Pacífico, pp.1-23. EL COLMEX.

Sandí, M. V. y López, Z. D. (2007). El amanecer del sudeste asiático: Experiencias de Singapur y Malasia. En Revista Centroamericana de Administración Pública, (52-53), pp. 367-383.

Schiavon, U. J. (2014). “La teoría de la interdependencia”. En Schiavon, M.A., et al. (Coord.), Teorías de las relaciones internacionales en el siglo XXI: Interpretaciones críticas desde México. México, Benemérita Universidad Autónoma de Puebla / Colegio de San Luis / UABC / UANL / Universidad Popular Autónoma del Estado de Puebla.

See, T. P; Wilhelmy, von W., M. y Fajardo, V. M. (2007). El Sudeste asiático: estructura y cambios en sus relaciones internacionales. (156), pp. 926. Instituto de Estudios Internacionales de la Universidad de 
pISSN: 2395-8758

eISSN: en trámite

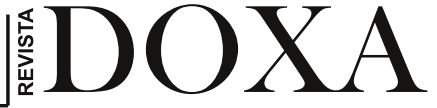

Chile.

Sondhi, S. (2007). International Relations. Search For Security and Development. New Delhi: South Asian Publishers PVT LTD.

Thompson, R. C. (1994). The Pacific Basin since 1945. Harlow, Essex: Longman.

Tzili, A. E. (2007). Filipinas. En Anuario Asia Pacífico 2017. El Colegio de México,

pp.317-336.

Vega, S. E. y Hernández, P. Y. (2015). Crisis ecológica como amenaza a la gobernanza en el sudeste asiático. En Ramírez, M. K., Reyes, R. M. y Figueroa, R. A. (coords.), Gobernanza y políticas públicas, pp.225-242. México: UABC.

Vilar, C. (2011). El sudeste asiático. Ideal para mochileros. Recuperado de, http://www.mundo-nomada.com/articulos/el-sudeste-asiaticoideal-para-mochileros 